\title{
Application of Calorimetric Method for Loss Measurement of a SynRM Drive System
}

\author{
Lassi Aarniovuori, Member, IEEE, Jere Kolehmainen, Member, IEEE, Antti Kosonen, Markku \\ Niemelä, Huifeng Chen, Member, IEEE, Wenping Cao, Senior Member, IEEE and \\ Juha Pyrhönen, Member, IEEE
}

\begin{abstract}
Synchronous reluctance motors (SynRMs) are gaining in popularity in industrial drives due to their permanent magnet-free, competitive performance and robust features. This paper studies the power losses in a $90 \mathrm{~kW}$ converter-fed SynRM drive by a calorimetric method in comparison of the traditional input-output method. After the converter and the motor were measured simultaneously in separate chambers, the converter was installed inside the large-size chamber next to the motor and the total drive system losses were obtained using one chamber. The uncertainty of both measurement methods is analyzed and discussed.
\end{abstract}

Index Terms-Calorimeter, converter, efficiency, electric drive, induction motor, measurement, synchronous reluctance motors power loss, temperature, uncertainty, variable speed drive, voltage-source converter.

\section{INTRODUCTION}

E LECTCRIC MOTORS form the most important type of load in the industry, consuming about $65-70 \%$ of the electric energy [1]. Hence, thermal and efficiency issues are among the hot topics in the electrical machines and drives community [2].

In general, the electric motor efficiency is continuing to improve and this poses new challenges to the motor loss determination. New and more efficient constructions have to be verified by measurements. The usage of permanent magnets is rising the machine efficiency [3], but due to high prices, supply problems and temperature dependence of permanent magnets, there is a high demand for magnet free motor such as switched reluctance (SRM) [4] and SynRMs. In principle, the SynRMs represent an established and mature

Manuscript received March 9, 2015; revised August 24, 2015; accepted October 8, 2015.

Copyright (C) 2015 IEEE. Personal use of this material is permitted. However, permission to use this material for any other purposes must be obtained from the IEEE by sending a request to pubs-permissions@ieee.org

L. Aarniovuori, A. Kosonen, M. Niemelä, and J. Pyrhönen are with the Department of Electrical Engineering, Lappeenranta University of Technology (LUT), Lappeenranta, Finland (e-mail: lassi.aarniovuori@lut.fi; antti.kosonen@1ut.fi; markku.niemela@lut.fi; juha.pyrhonen@lut.fi)

J. Kolehmainen is with ABB Motors and Generators, Vaasa, Finland (email: jere.kolehmainen@fi.abb.com)

H. Chen is with the Queens University of Belfast (QUB), Belfast, Northern Ireland UK (e-mail: h.chen@qub.ac.uk)

W. Cao is with the School of Engineering and Applied Science, Aston University, Birmingham, U.K. (email: w.p.cao@aston.ac.uk) technology, but the modern frequency converter control may lead to new features and properties of the motor.

Synchronous reluctance motors establish a promising technology with potentials to replace permanent-magnet synchronous motors (PMSMs) and induction motors as the main motor in industrial variable-speed applications. The SynRM rotor has neither windings nor magnets, thus improving the rotor reliability and eliminating the reliance on rare-earth-based permanent magnets. A high-inductance-ratio rotor structure is manufactured from punched or laser-cut electric sheets attached on a shaft.

Here, the losses of the converter and converter fed synchronous reluctance motor is obtained with two totally independent measurement systems. The losses of the both methods are compared and uncertainty is analyzed. For the first time it is showed that the calorimetric measurement system is also applicable to larger motors with reasonable measurement time. The calorimetric measurement results are further verified with the test sequence where the frequency converter losses are measured simultaneously with the SynRM in another calorimeter. To examine the reliability of the loss measurement results, the converter and the motor were then installed in the same chamber, and the nominal point measurement was repeated. The motor loss behavior is further studied by using a second converter with a slightly modified construction and measurement setup to show the significance of voltage sensing point in the variable speed drive system measurement.

This paper is organized as follows. Section II clarifies the need for other loss measurement method than commonly used input-output- method. The section III provides an introduction to the calorimetric measurement system used here. In Section IV, the laboratory measurements are carried out, and the uncertainty of the both measurement methods is analyzed in Section V. Section VI presents the loss measurement results with a modified converter. In Section VII, the total drive system losses are evaluated. Finally, Section VIII discusses the significance of the results, and Section IX concludes the paper.

\section{Challenges in Loss Measurements}

At the moment, there here is no official measurement methods or standard for the efficiency determination of the SynRM nor other types of converter fed machines. The IEC has launched 2013 a technical specification for converter-fed 


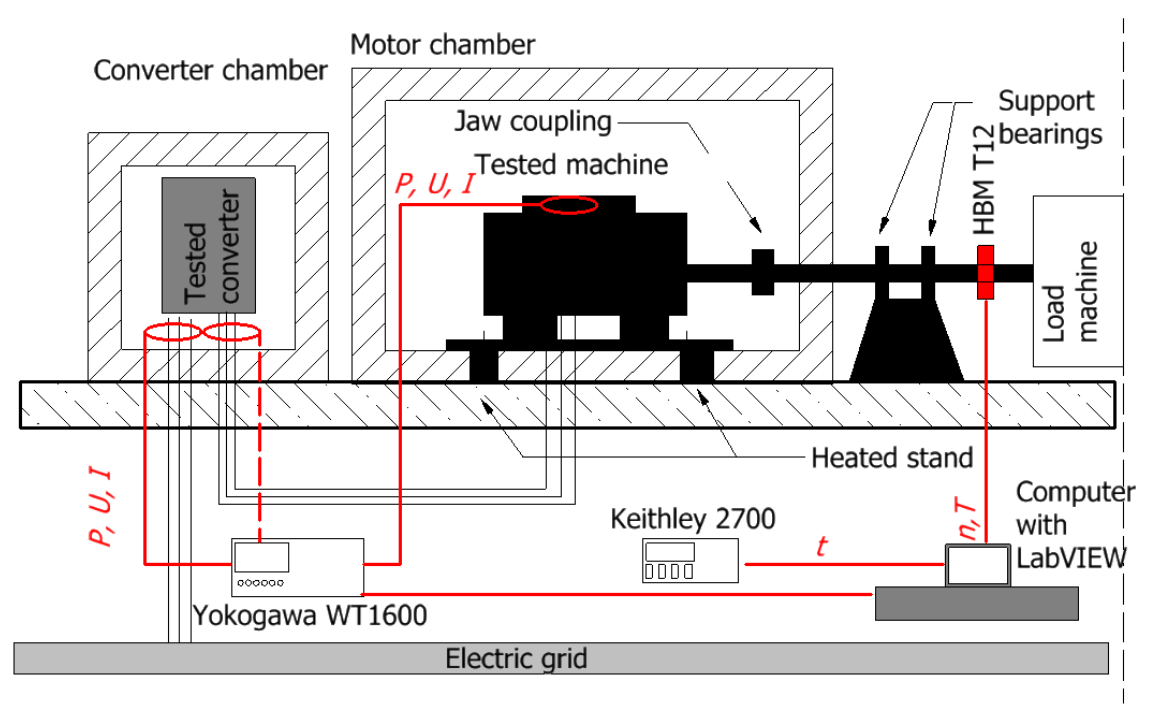

Fig. 1. Overview of the measurement setup and instrumentation. In the first measurement set, the converter output terminals were used as a voltage sensing points and in another set the motor terminals was used.

induction motor testing [5], [6]. There is an ongoing development of IEC 61800-9-2 that includes the testing methods and efficiency classes for converters and convertermachines systems. There are two alternative methods that can be used to determine the losses of a SynRM and other electrical machine types. The both methods are applicable to all direct-on-line or converter fed machines. The first is referred to as an input-output method and the second a calorimetric method. In the input-output method the losses are simply the difference between the measured input $\left(P_{\text {input }}\right)$ and output power $\left(P_{\text {output }}\right)$ as follows

$$
P_{\text {loss,io }}=P_{\text {input }}-P_{\text {output }}
$$

While in the calorimetric method the losses of the device are determined from the dissipated heat inside the chamber using the air flow and heat losses through the chamber walls

$$
P_{\text {loss,cal }}=q_{\mathrm{m}} c_{\mathrm{p}} \Delta T_{\mathrm{air}}+U_{\mathrm{wall}} S_{\mathrm{wall}} \Delta T_{\mathrm{wall}}
$$

where $q_{\mathrm{m}}$ is the mass flow rate, $c_{\mathrm{p}}$ the specific heat capacity of moist air, $\Delta T_{\text {air }}$ the temperature difference of moist air between the inlet and outlet tubes, $U_{\text {wall }}$ the overall heat transfer coefficient of the chamber, $S_{\text {wall }}$ the area of the chamber walls, and $\Delta T_{\text {wall }}$ the temperature difference across the chamber walls.

Both methods have their benefits and disadvantages, but they can be used also simultaneously as in this paper. The loss uncertainty in the input-output method is approaching infinity when the efficiency is approaching unity, therefore the reliability of the input-output -method is a concern when the device efficiency high such as in the case of converters [7].

Further, independent measurement methods make it possible to compare the uncertainties of the measurement methods. There are multiple reasons why the synchronous reluctance motor is an interesting test case for the loss measurements and efficiency determination. The measurement accuracy of the motor electric input power is affected by the
PWM voltage waveform and the inherently low power factor of the SynRM [8] while the calorimetric measurement method is not affected by the same factors than the input-output method.

The loss measurement uncertainty is reduced when the whole drive system is evaluated instead of the individual devices, the system efficiency is lower than the efficiency of the individual devices and there is no longer a need to measure the problematic PWM waveform electric power.

\section{CALORIMETRIC CONCEPT}

An overview of various loss measurement techniques for power electronics systems is given, the electrical methods are introduced briefly, and sources of measurement errors are discussed in [9]. Calorimetric systems are divided into four categories: open, closed, balance, and series types in [10]. Different kinds of calorimeters are constructed to determine the losses of electrical devices. These calorimeters can be divided into two basic types; open type with air as a coolant [11]-[14] and close type with water as a coolant [15]-[17]. Lately, the calorimetric systems have been mainly used to verify the losses of high-efficiency converters and a concern of electric power measurement accuracy with distorted waveforms is highlighted [18]-[21]. The calorimetric construction used in this study is a scalable, open- and balance-type calorimeter. The utilized concept has been used both for converter and motor measurements as presented in [22]-[26]. The concept has been verified to be an accurate and viable alternative to loss determination of variable-speed drives.

Here, two calorimeters were used simultaneously to obtain both the frequency converter and SynRM motor losses. A medium-size calorimeter that is capable to measure the heat losses up to $3 \mathrm{~kW}$ and has the internal dimensions of $1.0 \mathrm{~m} \times$ $1.0 \mathrm{~m} \times 1.0 \mathrm{~m}(l \times w \times h)$ was used to obtain the frequency converter losses. A large-size calorimeter that can measure heat losses up to $30 \mathrm{~kW}$ was used to obtain the motor losses. The internal dimensions of the large size chamber are $2.0 \mathrm{~m} \times$ 
$2.0 \mathrm{~m} \times 2.5 \mathrm{~m}$. The basic construction is a sealed box insulated with at least $100 \mathrm{~mm}$ thick polyurethane plane insulation.

The chamber exhaust blower that removes the heat losses from the calorimetric chamber is driven by a vector-controlled frequency converter with a speed feedback. The radial blower is located at the bottom of the chamber. The inlet tube is located at the top of the chamber. For the balance test, a basic steel-grid-fixed resistor is applied as a heater. The heater is also applied when the chamber is heated before the measurements.

A-class PT-100 temperature sensors with four-wire compensation circuits are applied to measure the temperatures. The inlet and outlet temperatures $\left(T_{\text {in }}\right.$ and $\left.T_{\text {out }}\right)$ are averaged from four sensors that are located in the inlet and outlet tubes. The tubes have a mixer (blower in the outlet) to equalize the temperature inside the tube before the temperature sensors. The inside temperature distribution of the chamber $\left(T_{\text {inside }}\right)$ is measured from a grid of 12 sensors in the medium-size calorimeter and from 16 sensors in the large size calorimeter. One sensor is used in the medium-size calorimeter and four in the large-size chamber (in the center of each wall) the outside temperature distribution of the chamber ( $\left.T_{\text {outside }}\right)$ There are diffuser plates in the front of the inlet and outlet tubes to remove direct heat radiation to the tubes. This removes the effect of the locations of the heat sources in the chamber on that proportion of the heat power that is transferred by the air flow. Therefore, the location of the heat source is only affecting that proportion of the losses that are a result of the heat leakage through the walls. All the measurements, controls, algorithms, and data processing are implemented to a control computer via a LabVIEW interface. Fig. 1 illustrates the experimental setup of the calorimeter.

In the motor setup, the extra shaft piece with support bearings makes it possible to use the jaw coupling with insulation to block the conduction losses through the shaft and breach the insulation in the wall with a tight fitting. To prevent heat leakage through motor bed, in the heated stand there are four $10 \mathrm{~W}$ power resistors installed in each of the motor supports together with two Pt-100 temperature sensors. The first temperature sensor is located in the top of the iron cylinder and another one vertically in halfway between the insulation. By adjusting the resistor power with a programmable DC-power supply the temperature difference between the sensors can be set to zero and no heat flux is presented in the supports.

\section{LABORATORY MEASUREMENT}

The electrical input power was measured using a Yokogawa WT1600 power analyzer equipped with a high-precision Hitec CURACC current measurement system. The voltages were recorded from the frequency converter terminals. The currents were measured right outside the calorimeter chamber of the converter. The rotational speed and the shaft torque were measured with a $1000 \mathrm{Nm}$ HBM T12 torque transducer.

The nominal values of the motor under test are given in Table I. The measurement points are presented in Fig. 2 as a

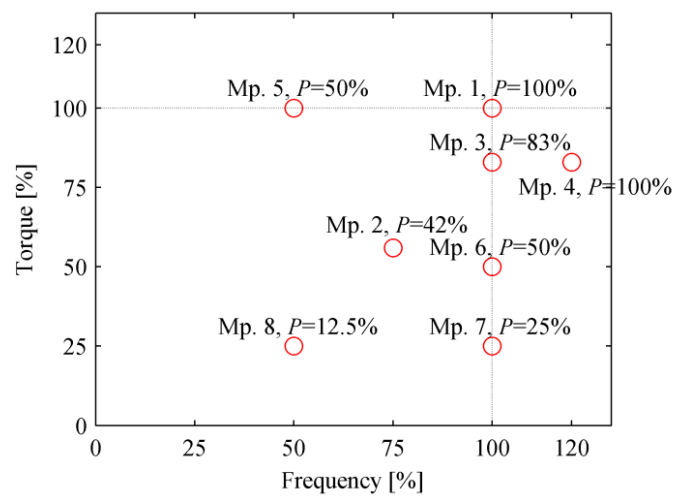

Fig. 2. Measurement points in the frequency-torque plane.

TABLE I

MOTOR NAME Plate VALUES

\begin{tabular}{l|c}
\hline \hline Winding connection & $\Delta$ \\
\hline \hline Nominal power, $P_{\mathrm{N}}(\mathrm{kW})$ & 90 \\
\hline Nominal current, $I_{\mathrm{N}}(\mathrm{A})$ & 202 \\
\hline Nominal voltage, $U_{\mathrm{N}}(\mathrm{V})$ & 370 \\
\hline Nominal torque, $T_{\mathrm{N}}(\mathrm{Nm})$ & 573 \\
\hline Nominal frequency, $f_{\mathrm{N}}(\mathrm{Hz})$ & 50 \\
\hline Nominal speed, $n_{\mathrm{N}}(\mathrm{rpm})$ & 1500 \\
\hline
\end{tabular}

frequency-torque plane with relative shaft powers. The target of these measurements is to define the total drive system losses. The electric input and output powers of the frequency converter are measured with a power analyzer and the mechanical power and speed with a torque transducer. Measurement point 1 (nominal power point) is measured twice with a slightly different measurement system configuration. Two calorimeters are used to obtain the frequency converter and motor losses simultaneously in measurement points 1,5 , 6,7 , and 8 . In measurement points 2 to 4 , only the motor losses are obtained with the calorimeter.

\section{A. Measured Frequency Converter Losses}

The frequency converter losses are much easier to determine with the calorimeter than the motor losses because only the power cables have to be led through the insulated chamber, and the ventilation blower can be driven easily with an external DC power supply. In this case, the frequency converter blower rotates at the full speed during the main and balance tests. The frequency converter loss results are given in Fig. 3.

The results of the frequency converter loss measurement by the two measurement methods agree well with one another. The calorimetric and input-output loss results in measurement point 1 are from different heat runs, but the frequency converter output power difference between the two runs is $70 \mathrm{~W}$ and the current difference $0.1 \mathrm{~A}$, so the loss results are fully comparable. In measurement point 5 there is no clear indication of why there is a larger difference in loss results than in the rest of the points.

\section{B. Measured Motor Losses}

The basic idea of the balance-type calorimeter is to define the heat losses of a device by a balance test of a reference heater. During the balance tests, the motor is rotated with the load machine in the same direction and with the same speed as 
a)

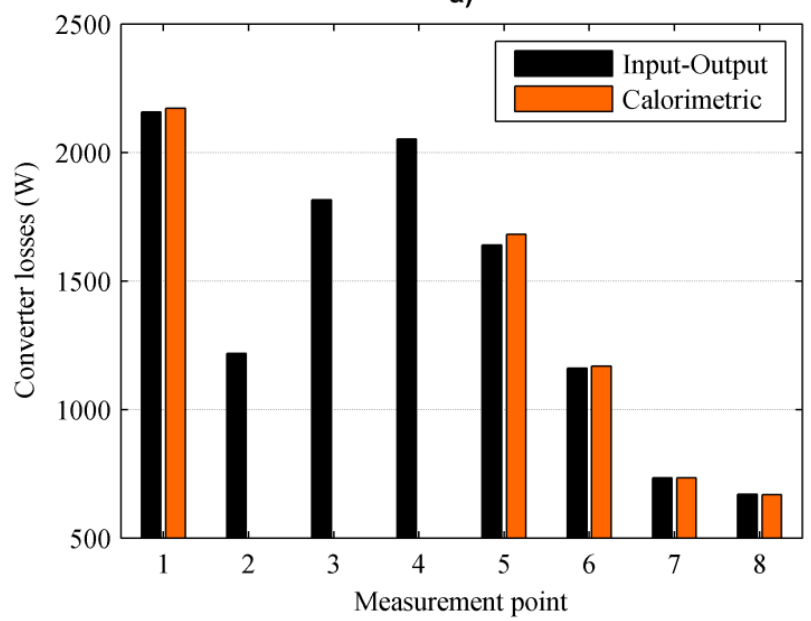

b)

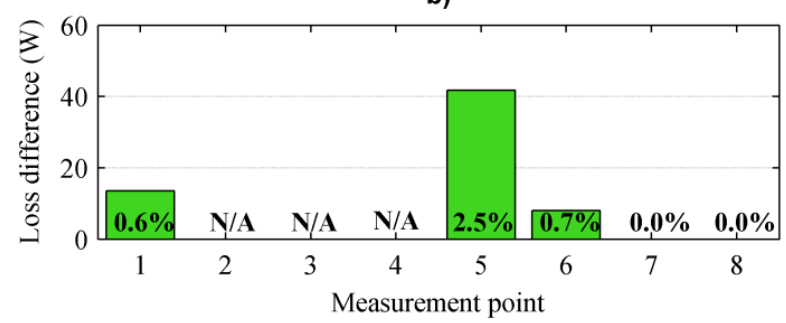

Fig. 3. Frequency converter loss results.

the main test to keep the ventilation conditions in the calorimetric chamber equal in both tests. This, naturally, means that there is a certain amount of friction loss present in the chamber. The measurement system is presented in Fig. 1 and its operation is described in [26].

The accurate determination of friction and windage losses is crucial for the accurate calorimetric total loss determination of the motor, because the motor has to keep running during the balance test. The reference power during the balance test is the sum of the DC heater power and the friction and windage losses. Hence, the error in the friction and windage losses is also present in the total loss of the motor.

The friction and windage losses constitute a relatively large proportion of the losses of a high-efficiency machine, and they are temperature dependent [31]. In this study, the cold machine friction and windage losses were examined. The friction and windage losses are over $10 \%$ of the total motor losses. The calorimetric measurement system cannot be used to obtain the friction and windage losses because of the possible changes in the air circulation inside the measurement chamber. Consequently, they have to be measured by some other method and are a major uncertainty contributor. Moreover, the friction and windage losses have to be examined carefully when the measured losses are compared with the simulated ones.

Two alternative and independent methods were used to obtain the friction and windage losses. The friction and windage losses at different speeds were obtained by mounting a $100 \mathrm{Nm}$ HBM T12 torque transducer and rotating the motor with the load machine (Fig. 1). After the total friction and windage losses of the system were obtained, the jaw coupling

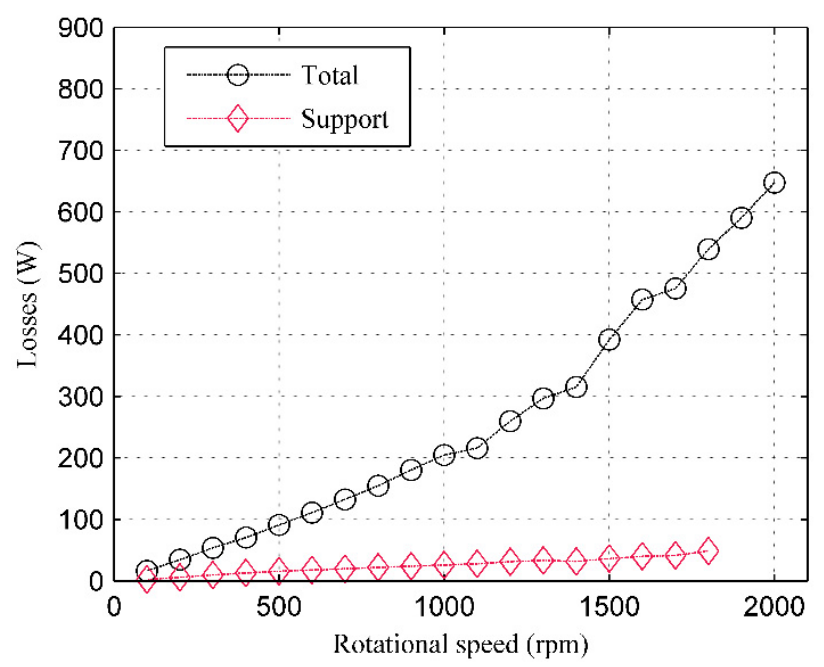

Fig. 4. Friction and windage losses. The total curve presents the cold machine friction and windage losses together with the support bearing losses. The support losses refer to the support bearing losses.

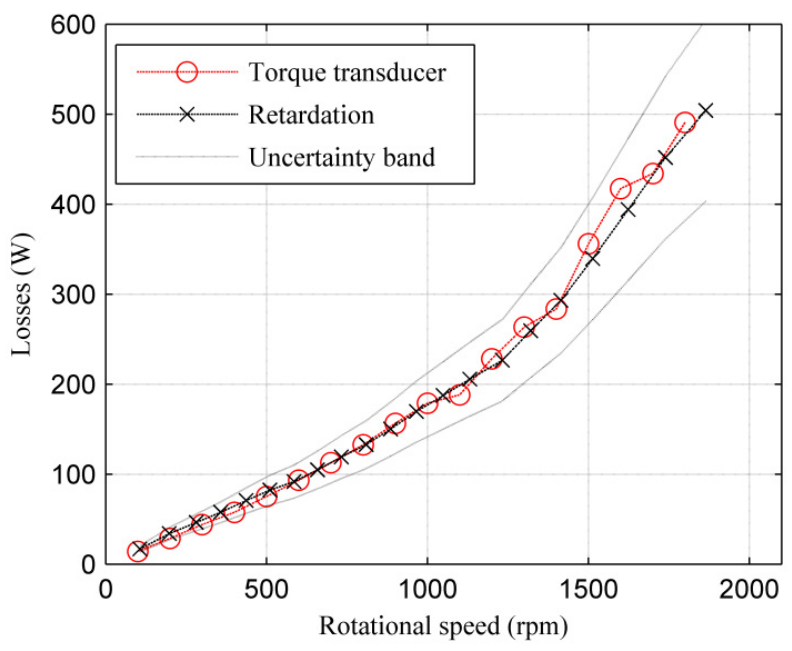

Fig. 5. Friction and windage losses and the defined $20 \%$ uncertainty band as a function of rotational speed obtained by a torque transducer and from the retardation test.

was uncoupled and the friction losses of the support bearings were measured accordingly. The results of the friction and windage loss measurements are presented in Fig. 4. The machine temperature in the test is the same as in the balance tests (around $35^{\circ} \mathrm{C}$. A no-load retardation test was made to verify the friction and windage losses. The retardation test was performed after the end of balance test to provide exactly same machine conditions also for this test. The two tests are totally independent of each other; the uncertainty of the first method comes from the torque transducer, and in the second test from the rotational speed meter, time, and inertia of the machine. The friction and windage losses as a function of rotational speed are presented in Fig. 5.

The friction and windage loss curves obtained by both methods have similar shapes, but the one obtained from the retardation test is much smoother. It is obvious that the retardation test is a more feasible and accurate method to determine the friction and windage losses as a function of rotational speed than the torque transducer. The torque 
a)

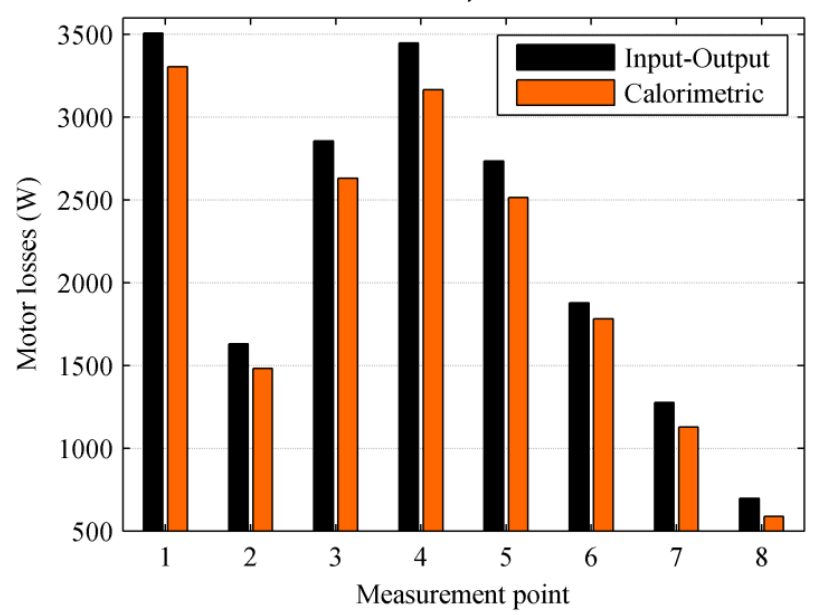

b)

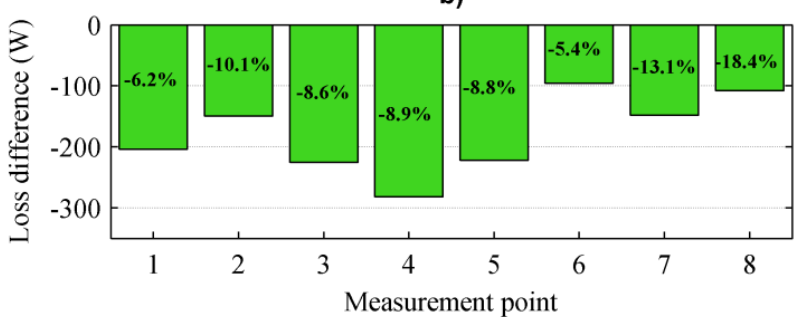

Fig. 6. Main caption. (a) Measured motor losses with the input-output and calorimetric methods. (b) Difference between the obtained loss results.

transducer accuracy is related to the full (nominal) range of the transducer, and therefore, when small values are measured, the accuracy is limited. Furthermore, the use of very small torque transducers raises a problem in the mechanical installation, and the transducer has to be protected against overtorque during acceleration and deceleration. On the other hand, the speed of the decelerating machine is easily measured with a one-second interval by inductive or optical sensors or even by hand-held tachometers. Naturally, the accuracy of the friction and windage losses obtained by a retardation test depends on the accuracy of the inertia value of the machine. The visual inspection of the results in Fig. 5 shows that the assumed $20 \%$ uncertainty in the friction and windage losses is reasonable.

In the calorimetric loss measurement analysis, the support bearing losses have been removed from the friction and windage loss measurement results. The friction losses of the support bearings have also been removed from the inputoutput motor losses. Both losses are given in Fig. 6.

Usually, the thermal equilibrium in the motor measurements is assumed to be achieved when the motor temperature rise rate is below $2 \mathrm{~K} / \mathrm{h}$. The tested machine in free air reaches the $2 \mathrm{~K} / \mathrm{h}$ temperature rise rate in four hours and $1 \mathrm{~K} / \mathrm{h}$ rise rate in five hours, respectively. When the machine is installed inside the calorimeter, the $2 \mathrm{~K} / \mathrm{h}$ temperature rise rate is reached after 2.5 hours and $1 \mathrm{~K} / \mathrm{h}$ after 3.5 hours. Here, the measurement results are gathered after seven hours during a full thermal equilibrium, when the temperature rise rate is below $0.1 \mathrm{~K} / \mathrm{h}$. The nominal point of the motor was measured twice. In the first run, the voltage was sensed from the converter terminals

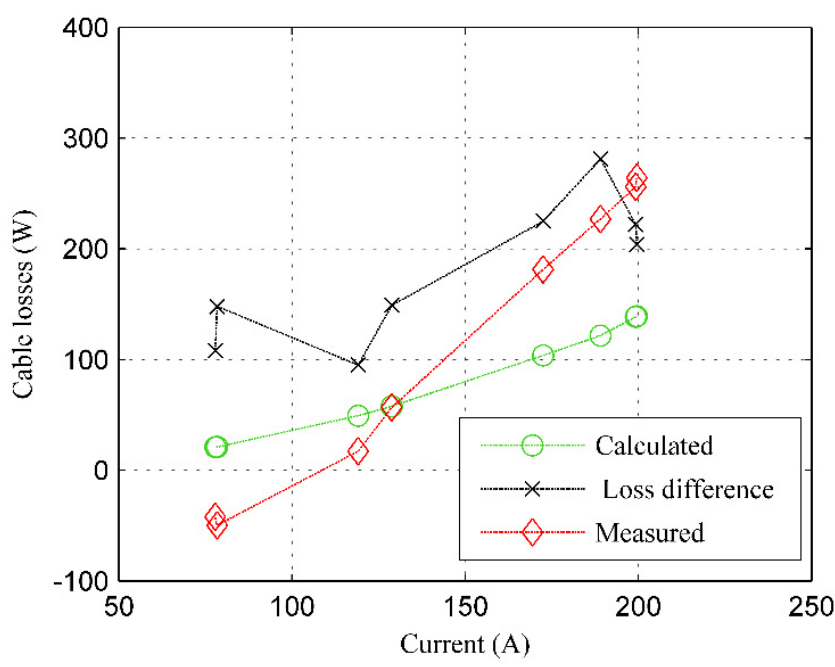

Fig. 7. Cable losses.

and in the second run from the motor terminals. In the second heat run, the loss difference between the two methods was only $2 \mathrm{~W}$. In all other points, the voltage has been sensed from the converter terminals, and the motor losses also include the cable losses. The voltage measurement point was chosen this way, because the cable losses constitute a smaller part of the motor losses than the converter losses. It must be noted that the accuracy of the both methods is reduced in partial load conditions. A $1500 \mathrm{~W}$ bias power (resistor heater) was used in all other points than the nominal load point to increase the system losses to a more suitable power level for the calorimetric measurement system.

\section{Cable Losses}

The total length of the cables from the converter to the motor is $11.2 \mathrm{~m}$. The first cable section is $8.5 \mathrm{~m}$ long $6 \times 70$ $\mathrm{mm}^{2}$ (2 per phase), which is extended with a $2.7 \mathrm{~m}$ long 120 $\mathrm{mm}^{2}$ cable. The cable losses are estimated by applying the method presented in [27] to calculate the cable losses. The measurement points are repeated and the cable losses are also measured using a WT1600 power analyzer, which is equipped with six power modules. The voltage is sensed directly from the converter (power modules 1 to 3 ) and the motor terminals (power modules 4 to 6 ) using the power analyzer input modules. The corresponding phase current message from the current measurement system is fed to the power modules. Thus, the power modules 1 and 4,2 and 5 , and 3 and 6 measure the same currents. There was no detectable current difference between the corresponding power modules. The power difference between the cable ends gives one estimate of the cable losses. Naturally, the uncertainty of this kind of a measurement is very large, yet adequate to yield the motor loss difference when the frequency converter or motor terminals are used as voltage sensing points. The difference between the calorimetric and input-output loss measurement and the calculated and measured cable losses are presented in Fig.7. The cable losses are presented as a function of motor current, and it should be kept in mind that the fundamental wave frequency is different for the different load points and 
a)

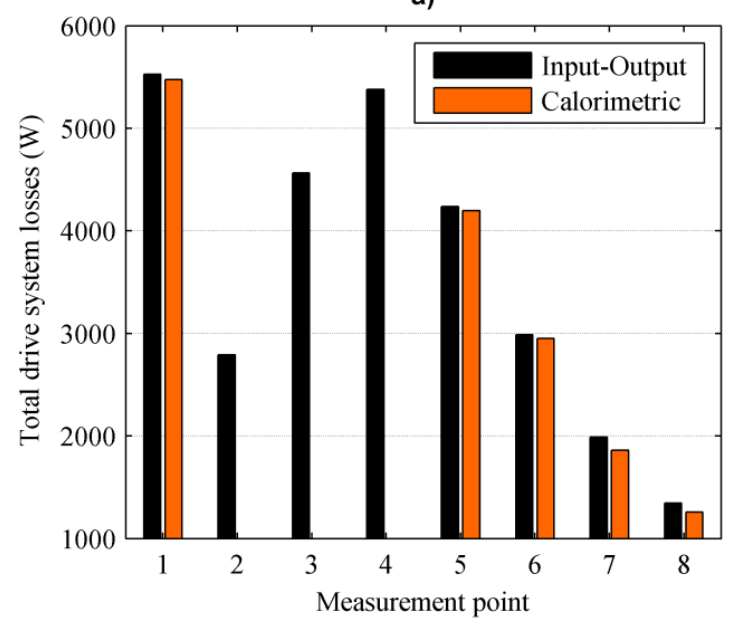

b)

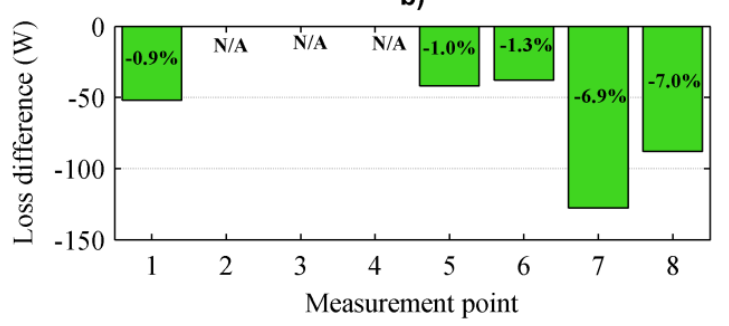

Fig. 8. Total drive system losses. (a) Measured with the input-output and calorimetric methods. (b) Difference between the obtained loss results.

may have an effect on the cable losses.

The measured negative cable losses indicate erroneous measurement results. Therefore, another nominal point measurement was conducted (200 A current), where all power analyzer channels were used to measure the same PWM power at the motor terminals. The difference in the two power figures was only $9.6 \mathrm{~W}$, and thus, it cannot be explained by the differences in the power modules of the power analyzer. Further investigations and measurements have to be made to determine the exact source of this phenomenon.

\section{Total Drive System Losses}

The uncertainty of the input-output loss determination is reduced when the total drive losses instead of the motor or converter losses are examined. The drive losses in Fig. 8 are given without the cable losses, which have been removed from the loss results.

\section{UNCERTAINTY ANALYSIS}

The uncertainty sources in the calorimetric measurement are different from the input-output measurement. The calorimeter can only measure the static operating point losses, and therefore, also the measurement values (electric and mechanical) that are used to obtain the loss results are calculated from 100 measurement values taken from $20 \mathrm{~s}$ intervals. Ten smallest and ten largest values are removed, and the average of the remaining 80 values is used. The power analyzer update is $5 \mathrm{~s}$ and the sample rate is 200 kilosamples per second.

The target of these measurements was to determine the
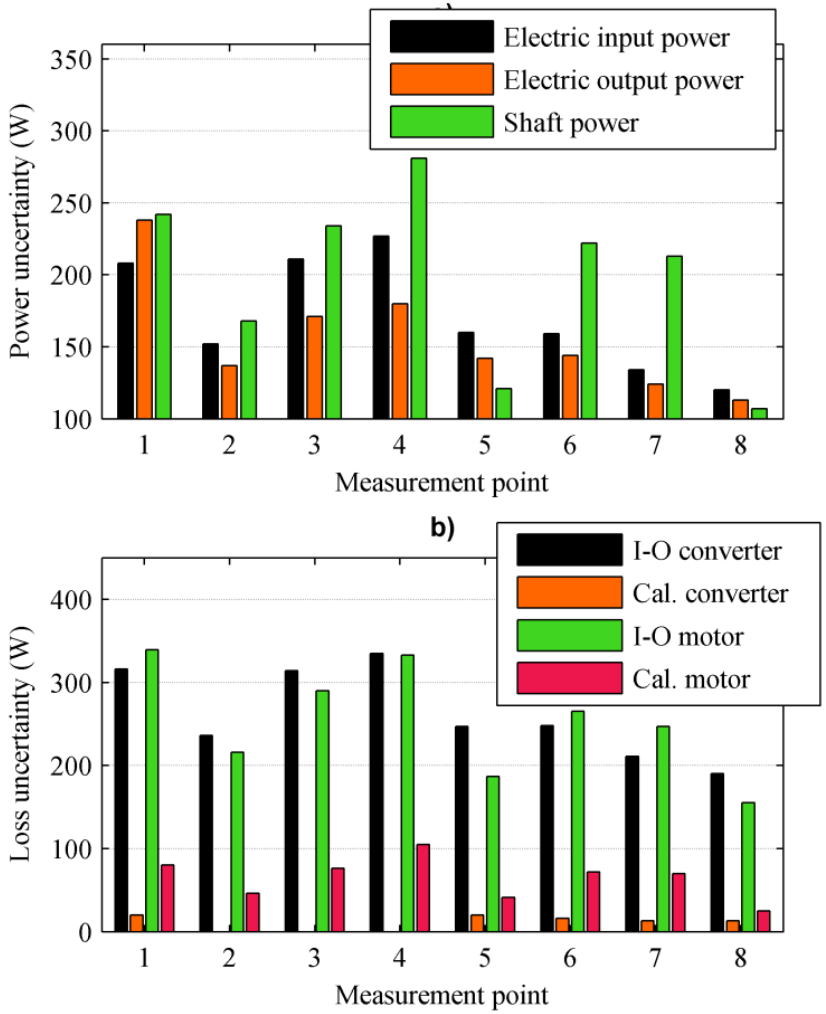

Fig. 9. Uncertainties. (a) Power measurement. The electric input and output powers are the frequency converter input and output powers measured with Yokogawa WT1600 equipped with Zero-Flux current sensors. The shaft power is the combined uncertainty of the speed and torque measured with HBM T12. (b) Loss measurement. Notation 'I-O' refers to the loss uncertainty obtained by the input and output powers, and 'Cal.' indicates the calorimetric loss measurement uncertainty.

losses of the motor and the converter. Hence, it is reasonable to give a combined standard uncertainty, where the component uncertainties are combined to yield an overall uncertainty. In this case, the components are the input and output powers of the frequency converter and the motor, and the combined standard uncertainty is the device loss uncertainty. It is very unlikely that both input and output power measurement errors are at their extreme values with the same sign, and therefore, a more realistic estimate is obtained by the root sum square (RSS) method, where the total uncertainty is the square root of the sum of squares of the input and output power standard uncertainties.

\section{A. Electric Power Measurement}

The Hitec Zero-Flux current measurement system with 600 A peak (424 A RMS) capability sensors is used for the current measurement. The AC accuracy for this kind of current output type sensors is $0.01 \%$ of reading $+0.002 \%$ of range, and the phase displacement is below $0.01^{\circ}$. The current measurement system gives a $0-1$ A current signal that is read by the power analyzer. In these measurements for the nominal load point with a $200 \mathrm{~A}$ current, the total current uncertainty of the current measurement system is 0.014 A RMS, which results in a $12 \mathrm{~W}$ uncertainty in the total electric power of $93.51 \mathrm{~kW}$. The phase displacement adds a $15 \mathrm{~W}$ uncertainty to the power value when the power factor is 0.74 . 
The electric power is measured with a three powers four wire $(3 \mathrm{P} 4 \mathrm{~W})$ configuration, and the voltage is measured against a virtual zero point. Even in the case of the PWM supply, over $98 \%$ of the active power is at the fundamental wave frequency, and it is thus reasonable to calculate the uncertainty based on the fundamental wave accuracies. The situation is similar also on the input side of the frequency converter.

The basic one-year power accuracy of the Yokogawa WT1600 power analyzer is $0.15 \%$ of reading $+0.075 \%$ of range + the power factor error [28]. The Yokogawa accuracies are within the "guaranteed specification limits. Therefore, in the uncertainty calculation, the values can be treated as a rectangular distribution with a $100 \%$ confidence level. The current measurement errors have been added to the power analyzer error to get the total electric power uncertainty. The frequency converter input and output power uncertainty in each measurement point is given in Fig. 9 a). Basically, the uncertainties in the converter input and output powers are at the same level. For example, in the nominal load point, the highest uncertainty difference is a lower power factor on the motor side.

\section{B. Mechanical Power Measurement}

When measuring the shaft power, it should be kept in mind that the power is a product of speed and torque. The speed measurement system is totally different from the torque measurement system. Therefore, when the measurement target is the power, it does not suffice to analyze the torque uncertainty but also the uncertainty of the speed measurement has to be taken into account. Here, fully digital data transfer from the torque transducer to LabVIEW has been used, and no further uncertainties are produced by the voltage or frequency signal digitalization. The error sources in the mechanical power measurement are the influences of parasitic loads, repeatability, linearity, hysteresis, and the temperature effect on zero and span [29]. The speed and torque uncertainties are considered not to correlate. In the nominal point, the speed uncertainty is $0.23 \mathrm{rpm}$ and the total torque uncertainty $1.2 \mathrm{Nm}$. The mechanical power uncertainties $\left(P_{\text {mech }}\right)$ in each measurement point are given in Fig 9 a).

\section{Calorimetric Measurement Uncertainty}

The possible error sources in the calorimetric measurements are the differences in the air flow rates during the tests, heat and air leakages, and the reference heater power determination. Here, the uncertainty components of the calorimetric frequency converter measurement are a $10 \%$ uncertainty in the frequency converter blower power and a $0.4 \%$ loss uncertainty that originates from the calorimeter and DC heater reference power. In the balance-type calorimeter, the heat leakage differences between the main and balance tests must be controlled. The main heat leakage source in the calorimetric motor measurement is the shaft and motor bed. In this case, a jaw coupling with polyurethane insulation is used to disconnect the heat leakage path of the motor shaft. The maximum temperature difference between the inside and outside shaft temperatures is detected and added as a source to

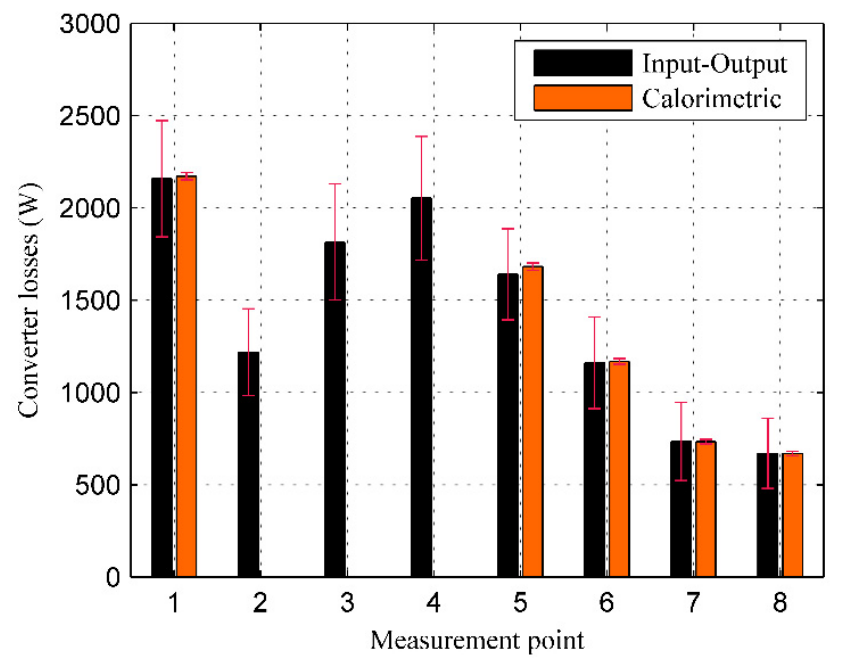

Fig. 10. Converter losses with measurement uncertainty bars.

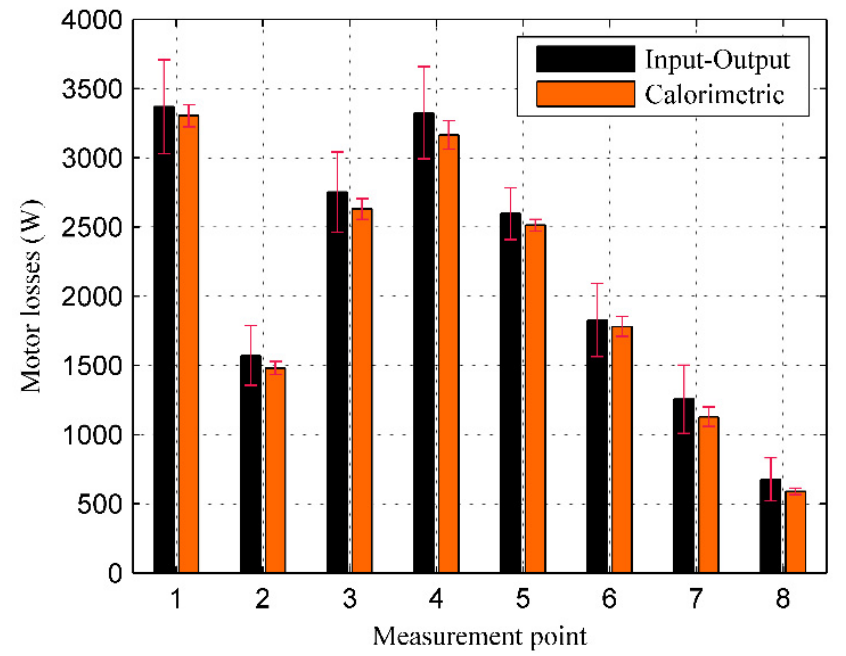

Fig. 11. Motor losses with measurement uncertainty bars.

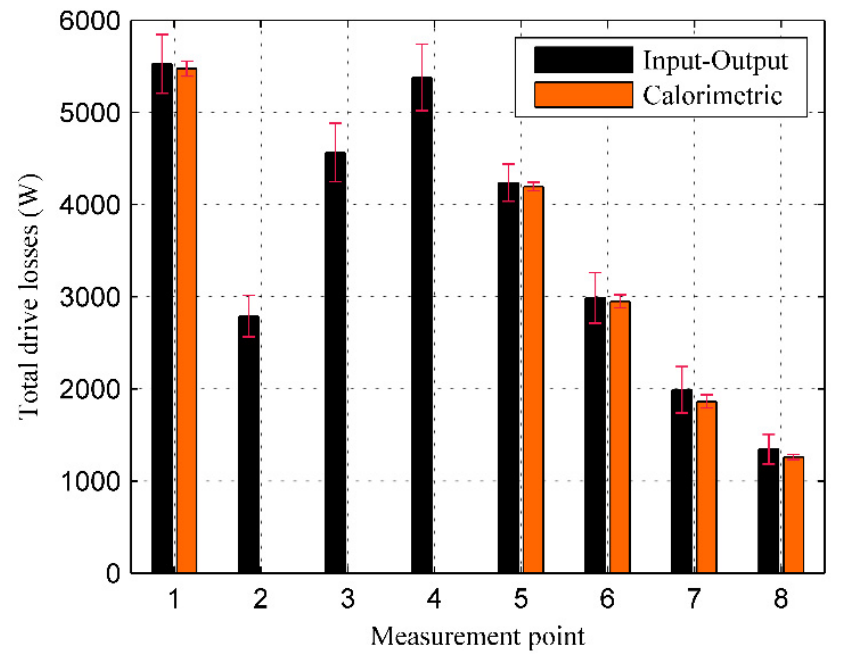

Fig. 12. Drive system losses with measurement uncertainty bars.

the uncertainty analysis. The insulated and heated stand is a feasible solution to build a motor bed for the motor calorimetric measurement. Because no temperature difference 
between the main and balance tests were detected, the uncertainty of the motor bed can be neglected. A $20 \%$ deviation in the motor friction and windage losses is assumed and added to the total motor loss uncertainty. In the case of motor measurement, also a $0.7 \%$ additional loss uncertainty that originates from the calorimetric system is included [23].

Both the input-output loss measurement uncertainty and the calorimetric loss measurement uncertainties are gathered in Fig. 9. The uncertainty limits of the converter and motor loss measurements with the input-output method are larger than with the calorimetric method. The loss measurement results with the loss uncertainty limits are given in Figs. 10-12. In the frequency converter measurements, the calorimetric measurement results are always within the uncertainty limits of the input-output loss measurement. The converter losses measured by the input-output method are outside of the calorimetric loss uncertainty limits only in measurement point 5. The motor losses obtained by the input-output method are within the calorimetric uncertainty limits in measurement points 1 and 6 , but in the rest of the measurement points they are slightly outside the limits. If slightly higher cable losses are assumed, all the motor measurement results are within both uncertainty limits. With both methods, the total drive losses are within the uncertainty limits in measurement points 1,4 , and 5 while the input-output loss measurement result is outside of the calorimetric uncertainty limits in points 7 and 8 .

\section{SECOND CONVERTER}

The first converter measurement results showed that the cable losses pose the main problem in the comparison of loss results between the two methods. Now, we can expect the calorimetric converter loss result to be very close to the inputoutput loss result with this measurement setup, and therefore, the voltage is measured at the motor terminals. The cable losses can be determined by subtracting the calorimetric loss result from the input-output result. The motor is measured

a)

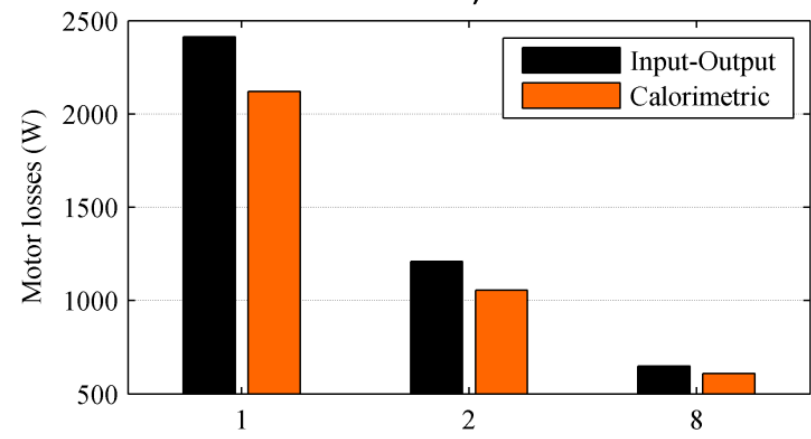

b)

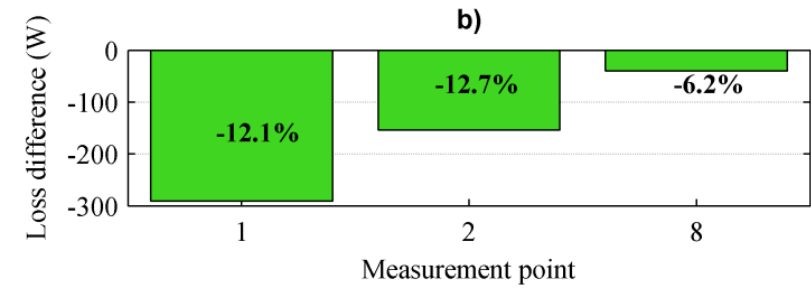

Fig. 13. Converter. (a) Losses. (b) Loss difference. a)

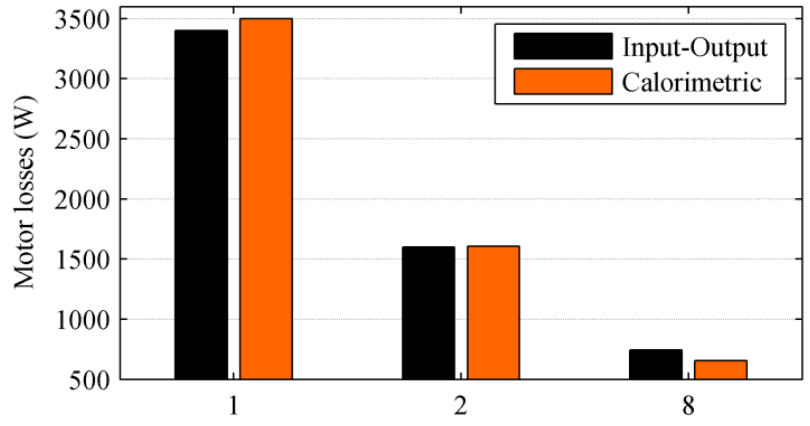

b)

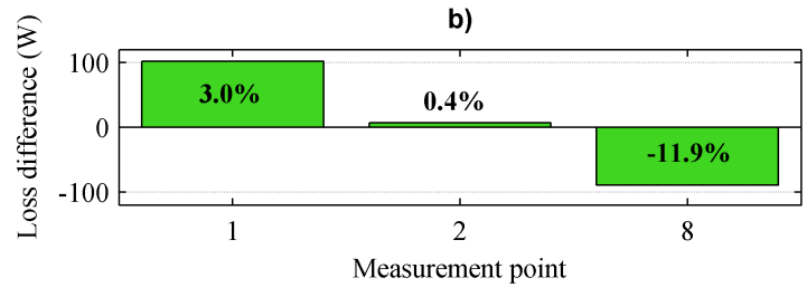

Fig. 14. Test result for the motor. (a) Losses. (b) Loss difference.

a)

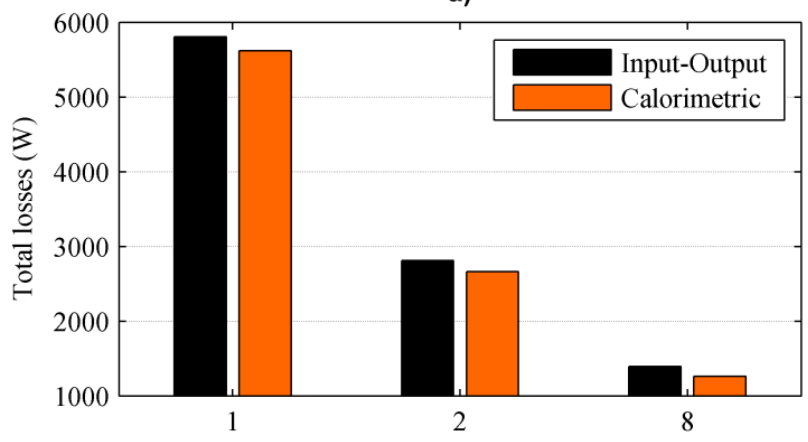

b)

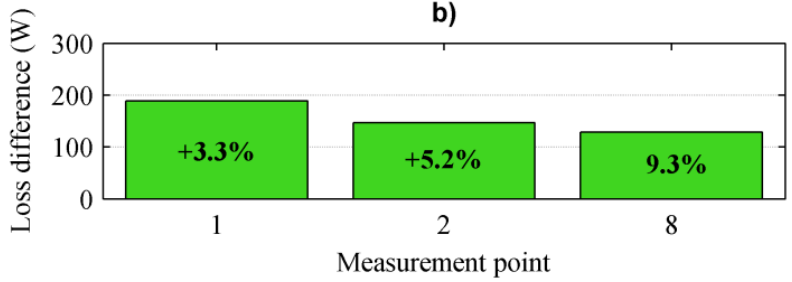

Fig. 15. Drive system. (a) Total losses. (b) Loss difference.

with the second converter in measurement points 1,2 , and 8 . The input-output and the calorimetric loss measurement results are given in Figs. 13-15, which support the results obtained above.

When inspecting the total drive system losses, the cables are outside of the calorimetric measurement, and thus, the calorimeter results do not include cable losses. The calorimetric total drive loss results are slightly lower than the results obtained by the input-output measurement.

The converter loss results are now higher with the inputoutput method than with the calorimetric method. The difference is not only from the cable losses. It appears that the power analyzer cannot accurately measure the converter PWM signal from the motor terminals. Obviously, there are reflected voltage pulses and possible standing-wave voltages at the motor terminals as a result of the PWM switching. 


\section{Total DRIVE System Losses}

It is challenging to verify the accuracy of the calorimetric method. In our case, after the converter and the motor were measured simultaneously in separate chambers, the converter was installed inside the large-size chamber next to the motor. The same cable was installed inside the chamber. Again, current sensors were provided between the converter and the motor to detect the variation in the motor operating point and to separate the losses between the motor and the converter. The tests were carried out in the nominal point. The measurement results are given in Table II. The key results from the nominal point measurement are repeated here for comparison. The new results with the both devices in the same chamber are indicated by a double asterisk. In the nominal load point, the difference between the two input-output loss measurements is only $19 \mathrm{~W}$ and between the two calorimetric loss measurements is $205 \mathrm{~W}$. In the first run, where the converter and the motor are installed in separate chambers, the calorimeter cannot see the cable losses, but they are included in the second run. The cable losses (around $200 \mathrm{~W}$ ) are not included in the calorimetric result of the first run but they are incorporated in the second run.

\section{DISCUSSION}

To sum up, it is questionable how accurately the motor losses should be measured for example in type testing. In our case, both methods could easily be applied to obtain the motor losses with the $15 \%$ loss tolerance given in [32]. There are numerous factors affecting the motor loss measurement results; for instance air temperature, humidity, density, and barometric air pressure affect the motor cooling system performance. The bearing lubrication and temperature have an effect on the friction losses. The thermal conduction paths through the motor bed and shaft can vary in different test places. It is thus obvious that accurate loss determination of high-efficiency devices is a challenging task. A heat source similar to a frequency converter can be easily constructed and used to mimic the frequency converter losses in a calorimetric measurement. A metal frame with a DC blower and resistors is a suitable heat source for calorimetric system calibration. However, because of the rotating mechanics, accurate verification of the motor measurement is more difficult. Further, although the calorimetric measurement method can be

TABLE II

\begin{tabular}{c|c|c}
\multicolumn{3}{c}{ MEASUREMENT RESULTS } \\
\hline \hline $\begin{array}{c}\text { Measured } \\
\text { point }\end{array}$ & 1 & $1^{*}$ \\
\hline \hline$P_{\text {mech }}(\mathrm{kW})$ & 90.03 & 90.05 \\
\hline$I_{\text {motor }}(\mathrm{A})$ & 199.4 & 199.6 \\
\hline$T_{\text {chamber }}\left({ }^{\circ} \mathrm{C}\right)$ & 35.0 & 32.7 \\
\hline$P_{\text {io,con. }}(\mathrm{W})$ & 2158 & 2240 \\
$P_{\text {io,mot. }}(\mathrm{W})$ & 3508 & 3445 \\
\hline$P_{\text {io,drives. }}(\mathrm{W})$ & 5666 & 5685 \\
\hline$P_{\text {cal,con. }}(\mathrm{W})$ & 2171 & - \\
\hline$P_{\text {cal,mot. }}(\mathrm{W})$ & 3304 & - \\
\hline$P_{\text {cal,drives. }}(\mathrm{W})$ & 5475 & 5680 \\
\hline
\end{tabular}

considered slow and laborious, it can be used to support the reliability of the input-output loss measurement.

The PWM-fed induction motor as well other motor types should be easily measured with a similar accuracy as the SynRM presented here. The authors are of the opinion that with adequate equipment the input-output method can also be used in the type testing of PWM-fed motors with a reasonable accuracy.

It should be kept in mind that the differences in the loss results presented here are actually quite small. In the nominal point, the $100 \mathrm{~W}$ loss equals to $0.1 \%$ of the input or output power. It is pointed out that the current operative IEC motor efficiency measurement standard [33] requires an instrumentation accuracy of $0.2 \%$ for the power measurement device for sinusoidal supply waveforms.

\section{CONCLUSION}

The paper has presented a calorimetric system suitable for measuring motor losses directly up to the frame size 315 . The input-output loss determination shows a good agreement with the calorimetric losses. The uncertainty limits of the inputoutput loss determinations are large, but the results are surprisingly close to the calorimetric results, even though the SynRM has a low power factor and the supply waveform is distorted because of the PWM supply. With both measurement methods, the SynRM efficiency is slightly higher than $96.3 \%$ in the nominal point.

The cable losses are in this case from 5 to $10 \%$ of the converter total losses. It was shown that the motor or converter loss results vary significantly when the voltage is measured directly from the converter or motor terminals; this difference cannot be explained by the cable losses only.

A problem with the calorimetric motor measurement is the friction and windage losses; nevertheless, it was shown that the friction and windage losses obtained by the retardation test and the torque transducer are close to each other; nevertheless, the retardation test is more practical to use.

It is evident that the loss uncertainty of the input-output measurement can be high in the case of high efficiency devices. A small change in relative large input or output power value will lead to large change in relative small loss value in the case of high efficiency device. Therefore, other independent methods is needed to prove the results and to benchmark the input-output measurement system.

The calorimetric measurement system is totally independent of the input-output loss measurement, and when the losses obtained by both measurement systems are within the uncertainty limits, we can expect the results to be close to the absolute losses. Uncertainties are always present in the measurements, but their sources can be controlled when known. Moreover, the uncertainty limits presented in this paper are reasonable. The calorimetric method will be of relevant more importance over the input-output method when the efficiencies of the motors are further increased. 


\section{REFERENCES}

[1] F.J.T.E. Ferreira, J.A.C. Fong, and A.T. de Almeida, "Ecoanalysis of variable-speed drives for flow regulation in pumping systems," IEEE Trans. Ind. Electron., vol. 58, no. 6, pp. 2117-2125, June 2011.

[2] G.A. Gapolino and A. Cavagnino, "New trends in electrical machines technology_Part I," IEEE Trans. Ind. Electron., vol. 61, no. 8, pp. 4281-4285, August 2014.

[3] A. Boglietti, A.M., El-Refaie, O., Drubel, A.M., Omekanda, N. Bianchi, E.B. Agamloh, M. Popescu, A. Di Gerlando, J.B. Bartolo, "Electrical Machine Topologies: Hottest Topics in the Electrical Machine Research Community," IEEE Ind. Electron. Mag., vol. 8, no. 2, pp.18-30, June 2014

[4] Y. Qiang, B., Bilgin, A. Emadi, "Loss and Efficiency Analysis of Switched Reluctance Machines Using a New Calculation Method," IEEE Trans. Ind. Electron., vol. 62, no. 5, pp. 3072-3080, May 2015.

[5] A. Boglietti, A. Cavagnino, M. Cossale, A. Tenconi, S. Vaschetto, "Efficiency determination of converter-fed induction motors: Waiting for the IEC 60034-2-3 standard," in Proc. Energy Conversion Congress and Exposition (ECCE), 2013 IEEE, pp. 230-237, September 2013. Denver, Colorado.

[6] IEC 60034-2-3 TS, Rotating electrical machines - Part 2-3: Specific test methods for determining losses and efficiency of converter-fed AC induction motors, 2013.

[7] F. Forest, J.-J. Huselstein, S. Faucher, M. Elghazouani, P. Ladoux, T.A. Meynard, F. Richardeau, C. Turpin, "Use of opposition method in the test of high-power electronic converters," IEEE Trans. Ind. Electron., vol. 53, no. 2, pp. 530-541, April 2006.

[8] Y. Wang, D. Ionel, D.G. Dorrell, S. Stretz, "Establishing the Power Factor Limitations for Synchronous Reluctance Machines (Accepted for publication)," IEEE Trans. Magn., to be published.

[9] C. Xiao, G. Chen, and W.G.H. Odendaal, "Overview of power loss measurement techniques in power electronics systems," IEEE Trans. Ind. Appl., vol. 43, no. 3, pp. 657-664, May/June 2007.

[10] W. Cao, G. M. Asher, X. Huang, H. Zhang, I. French, J. Zhang, and M. Short, "Calorimeters and techniques used for power loss measurements in electrical machines," IEEE Instrum. Meas. Mag., vol. 13, no. 6, pp. 26-33, December 2010.

[11] B. Baholo, P.H. Mellor, D. Howe, and T.S. Birch, "An automated calorimetric method of loss measurement in electrical machines," $J$. Magn. Magn. Mater., vol. 133, no. 1-3, pp. 433-436, May 1994.

[12] A. Jalilian, V.J. Gosbell, B.S.P. Perera, and P. Cooper, "Double chamber calorimeter (DCC): a new approach to measure induction motor harmonic losses," IEEE Trans. Energy Convers., vol. 14, no. 3, pp. 680685, September 1999.

[13] K.J. Bradley, W. Cao, and J. Arellano-Padilla, "Evaluation of stray load loss in induction motors with a comparison of input-output and calorimetric methods," IEEE Trans. Energy Convers., vol. 21, no. 3, pp. 682-689, September 2006.

[14] W. Cao, K.J. Bradley, and A. Ferrah, "Development of a high-precision calorimeter for measuring power loss in electrical machines," IEEE Trans. Instrum. Meas., vol. 58, no. 3, pp. 570-577, March 2009.

[15] S. Weier, M.A. Shafi, and R. McMahon, "Precision calorimetry for the accurate measurement of losses in power electronic devices," IEEE Trans. Ind. Appl., vol. 46, no. 1, pp. 278-284, January/February 2010.

[16] E. Ritchie, J.K. Pedersen, F. Blaabjerg, and P. Hansen, "Calorimetric measuring systems," IEEE Ind. Appl. Mag., vol. 10, no. 3, pp. 70-78, May/June 2004.

[17] B. Szabados and A. Mihalcea, "Design and implementation of a calorimetric measurement facility for determining losses in electrical machines," IEEE Trans. Instrum. Meas., vol. 51, no. 5, October 2002, pp. 902-907.

[18] D. Christen, U. Badstuebner, J. Biela, J.W. Kolar, "Calorimetric Power Loss Measurement for Highly Efficient Converters," in Proc. International Power Electronics Conference (IPEC), 2010, pp.14381445, June, 2010, Sapporo, Japan.

[19] R. Kamei, Tae-Woong Kim, A. Kawamura, "Accurate calorimetric power loss measurement for efficient power converters," in Proc. 37th Annual Conference on IEEE Industrial Electronics Society IECON 2011 pp. 1173-1178, November 2011, Melbourne, Australia.

[20] F.W. Fuchs, J. Schroder, B. Wittig, "State of the technology of power loss determination in power converters," 15th European Conference on Power Electronics and Applications (EPE), pp. 1-10, September 2013, Lille, France.
[21] M. Sverko, S. Krishnamurthy, "Calorimetric loss measurement system for air and water cooled power converters," 15th European Conference on Power Electronics and Applications (EPE), pp. 1-10, September 2013, Lille, France.

[22] A. Kosonen, L. Aarniovuori, J. Pyrhönen, M. Niemelä, and J. Backman, "Calorimetric concept for measurement of power losses up to $2 \mathrm{~kW}$ in electric drives," IET Electr. Power Appl., vol. 7, no. 6, pp. 453-461, July 2013.

[23] L. Aarniovuori, A. Kosonen, P. Sillanpää, and M. Niemelä, "Highpower solar inverter efficiency measurement by calorimetric and electric methods," IEEE Trans. Power Electron., vol. 28, no. 6, pp. 2798-2805, June 2013.

[24] L. Aarniovuori, A. Kosonen, M. Niemelä, and J. Pyrhönen, "Calorimetric measurement of variable-speed induction motor," in Proc. 20th Int. Conf. on Electrical Machines, Marseille, France, September 2012, pp. 870-876.

[25] A. Kosonen, L. Aarniovuori, J. Ahola, J. Backman, J. Pyrhönen, and M. Niemelä, "Loss definition of electric drives by a calorimetric system with data processing," IEEE Trans. Ind. Electron., vol. 61, no. 8, pp. 4432-4442, August 2014.

[26] L. Aarniovuori, J. Kolehmainen, A. Kosonen, M. Niemelä, and J. Pyrhönen, "Calorimetric and input-output loss determination of $90 \mathrm{~kW}$ SynRM," in Proc. 21th Int. Conf. on Electrical Machines, Berlin, Germany, September 2014.

[27] Canadian standards association (CSA) C838-13 - Energy efficiency test methods for three-phase variable frequency drive systems.

[28] Yokogawa Electric Corporation, "WT1600 Digital Power Meter User's Manual", $4^{\text {th }}$ edition, available at www.yokogawa.com.

[29] R. Schicker, G. Wegener, "Measuring torque correctly," Hottinger Baldwin Messtechnik GmbH, Germany, 2002.

[30] Evaluation of measurement data - Guide to the expression of uncertainty in measurement, Ed. 1, JCGM 100:2008, Sep. 2008, pp. 1-134.

[31] A. Boglietti, A. Cavagnino, and S. Vaschetto, "Induction motor EU standards for efficiency evaluation: The scenario after IEC 60034-2-1," in Proc. 37th Annu. Conf. on IEEE Industrial Electronics Society, pp. 2786-2791, Melbourne, Australia, November 2011.

[32] Rotating Electrical Machines-Part 1: Rating and performance, Ed. 11, IEC 60034-1, April 2004.

[33] Rotating Electrical Machines-Part 2-1: Standard Methods for Determining Losses and Efficiency of Rotating Electrical Machinery from Tests (Excluding Machines for Traction Vehicles), Ed. 1, IEC 60034-2-1, September 2007.

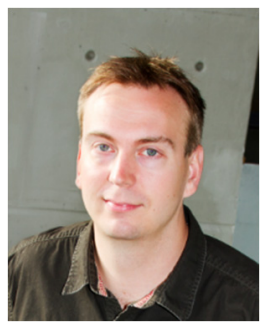

Lassi Aarniovuori (M'15) was born in Jyväskylä, Finland, in 1979. He received the M.Sc. and D.Sc. degrees in electrical engineering from Lappeenranta University of Technology (LUT), Lappeenranta, Finland, in 2005 and 2010, respectively.

$\mathrm{He}$ is currently a Post-doctoral Researcher in the Department of Electrical Engineering, LUT. His current research interests include the field of electric drives, especially simulation of electric drives, efficiency measurements, and calorimetric measurement systems.

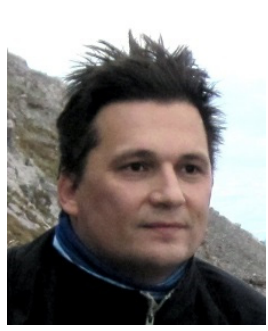

Jere Kolehmainen (M'09) received the M.Sc. and $\mathrm{Ph} . \mathrm{D}$. degrees in theoretical physics from the University of Jyväskylä, Jyväskylä, Finland in 1996 and 2000, respectively and D.Sc. degree in electrical engineering from the Aalto University, Helsinki, Finland in 2012.

$\mathrm{He}$ is currently working at $\mathrm{ABB}$ Motors and Generators, Vaasa, Finland. He has also been an Adjunct Professor of Rotating Electrical Machines, University of Vaasa, Vaasa Finland, since 2014. His research interests include synchronous and induction ac machines and electromagnetic modeling. 


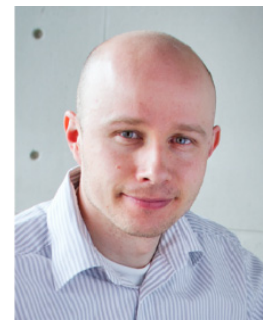

Antti Kosonen was born in Imatra, Finland, in 1980. He received the M.Sc. and D.Sc. degrees in electrical engineering from Lappeenranta University of Technology (LUT), Lappeenranta, Finland, in 2005 and 2008, respectively.

$\mathrm{He}$ is currently an Associate Professor in the Department of Electrical Engineering, LUT. His current research interests include power-to-gas systems, solar power, energy efficiency, calorimetric measurement systems, and power line

communication.

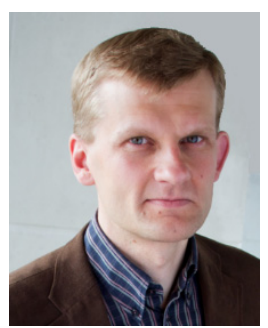

Markku Niemelä was born in Mäntyharju, Finland, in 1968. He received the B.Sc. degree in electrical engineering from Helsinki Institute of Technology in 1990, and the M.Sc. and D.Sc. (technology) degrees from Lappeenranta University of Technology (LUT), Lappeenranta, Finland, in 1995 and 1999, respectively.

$\mathrm{He}$ is currently a Senior Researcher with the Carelian Drives and Motor Centre in LUT. His current research interests include motion control, control of line converters, and energy efficiency of electric drives.

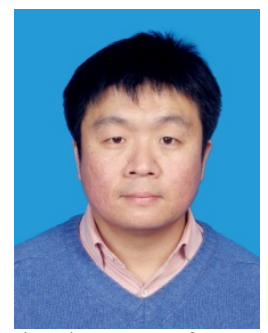

Huifeng Chen received the B.Eng. in electrical engineering from Northeastern University, Shenyang, China, in 2000; and the Ph.D. degrees in electrical and electronic engineering from Newcastle University, England, in 2010. He is currently a Research Fellow in the Energy, Power and Intelligent Control (EPIC) research cluster, Queen's University Belfast, UK. After his $\mathrm{PhD}$, he worked as a power electronic specialist in Siemens for powertrain development for EVs, and then worked on development of MMC VSC HVDC converters using press-pack devices in RXPE in China. His current research interests include high-precision calorimetric measurement technique, applications of high power semiconductor switches such as press-pack IGBT in the VSC HVDC converters, STATCOM and MV drives and so on

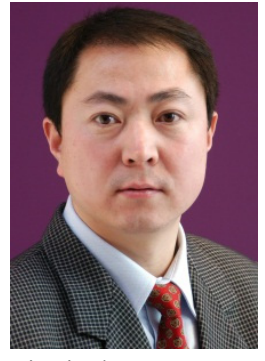

Wenping Cao (SM'11) received the B.Eng in electrical engineering from Beijing Jiaotong University, Beijing, China, in 1991, and the Ph.D. degree in electrical machines and drives from the University of Nottingham, Nottingham, U.K., in 2004.

$\mathrm{He}$ is currently a Marie Curie Fellow with the Department of Electrical Engineering and Computer Science, Massachusetts Institute of Technology, Cambridge, MA, U.S.A and a Chair Professor of Electrical Power Engineering with Aston University, Birmingham, U.K. He serves as an Associate Editor for IEEE Transactions on Industry Applications, IEEE Industry Applications Magazine and IET Power Electronics.

His research interests include fault analysis and condition monitoring of electric machines and power electronics.

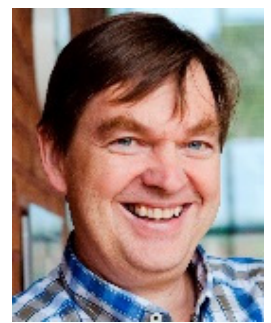

Juha J. Pyrhönen (M’06) born in 1957 in Kuusankoski, Finland, received the Doctor of Science (D.Sc.) degree from Lappeenranta University of Technology (LUT), Finland in 1991. He became Professor of Electrical Machines and Drives in 1997 at LUT. He is engaged in research and development of electric motors and powerelectronic-controlled drives. Prof. Pyrhönen has wide experience in the research and development of special electric drives for distributed power production, traction drives and high-speed applications. Permanent magnet materials and applying them in machines have an important role in his research. Currently he is also researching new carbon-based materials for electrical machines 